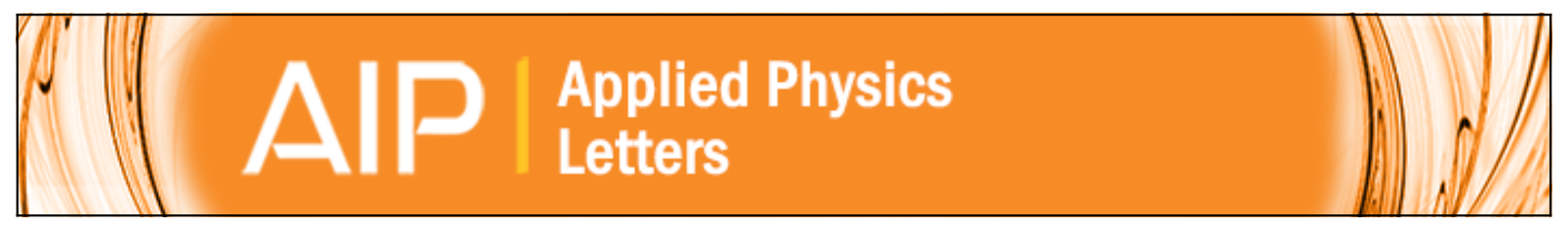

\title{
Novel high temperature multilayer electrode-barrier structure for high-density ferroelectric memories
}

H. D. Bhatt, S. B. Desu, D. P. Vijay, Y. S. Hwang, X. Zhang, M. Nagata, and A. Grill

Citation: Applied Physics Letters 71, 719 (1997); doi: 10.1063/1.119840

View online: http://dx.doi.org/10.1063/1.119840

View Table of Contents: http://scitation.aip.org/content/aip/journal/apl/71/5?ver=pdfcov

Published by the AIP Publishing

\section{Articles you may be interested in}

Characteristics of ferroelectric $\mathrm{Pb}(\mathrm{Zr}, \mathrm{Ti}) \mathrm{O} 3$ thin films having $\mathrm{Pt} / \mathrm{PtO}$ x electrode barriers

Appl. Phys. Lett. 79, 821 (2001); 10.1063/1.1391226

Electrical characteristics of metal-ferroelectric ( $\mathrm{PbZr} \times \mathrm{Ti}$ 1 $\times \mathrm{O} 3$ ) -insulator ( Ta 2 O 5 ) -silicon structure for nonvolatile memory applications

J. Vac. Sci. Technol. B 18, 2848 (2000); 10.1116/1.1319698

Low temperature processed $0.7 \mathrm{SrBi} 2 \mathrm{Ta} 2 \mathrm{O} 9-0.3 \mathrm{Bi} 3 \mathrm{TaTiO} 9$ thin films fabricated on multilayer electrodebarrier structure for high-density ferroelectric memories

Appl. Phys. Lett. 75, 2126 (1999); 10.1063/1.124938

Switching properties of $\mathrm{Pb}(\mathrm{Nb}, \mathrm{Zr}, \mathrm{Ti}) \mathrm{O} 3$ capacitors using $\mathrm{SrRuO} 3$ electrodes

Appl. Phys. Lett. 75, 1787 (1999); 10.1063/1.124820

Improvement of leakage currents of $\mathrm{Pt} /(\mathrm{Ba}, \mathrm{Sr}) \mathrm{TiO} 3 / \mathrm{Pt}$ capacitors

Appl. Phys. Lett. 70, 3053 (1997); 10.1063/1.118746

\section{AlP Re-register for Table of Content Alerts}

\section{Create a profile.

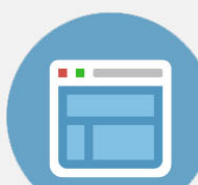 \\ Sign up today!}

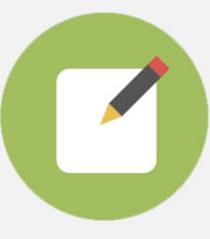




\title{
Novel high temperature multilayer electrode-barrier structure for high-density ferroelectric memories
}

\author{
H. D. Bhatt, S. B. Desu, D. P. Vijay, Y. S. Hwang, X. Zhang, and M. Nagata \\ Department of Materials Science and Engineering, Thin-Films Laboratory, Virginia Tech, Blacksburg, \\ Virginia 24061-0237
}

A. Grill
Electronic Materials and Structures Group, IBM Corporation, Yorktown Heights, New York 10598

(Received 4 November 1996; accepted for publication 14 April 1997)

This has been accomplished in the past using four/five separate electrode- and diffusion-barrier layers. In this letter, we report a novel $\mathrm{Pt}-\mathrm{Rh}-\mathrm{O}_{x} / \mathrm{Pt}-\mathrm{Rh} / \mathrm{Pt}-\mathrm{Rh}-\mathrm{O}_{x}$ electrode-barrier structure which acts as an electrode as well as a diffusion barrier for integration of the ferroelectric capacitors directly onto silicon deposited using an in situ reactive rf sputtering process. The electrodes have a smooth and fine grained microstructure and are excellent diffusion barriers between the $\mathrm{PbZr}_{0.53} \mathrm{Ti}_{0.47} \mathrm{O}_{3}(\mathrm{PZT})$ and $\mathrm{Si}$ substrate and exhibit good thermal stability up to very high processing temperatures of $700{ }^{\circ} \mathrm{C}$. The ferroelectric (PZT) test capacitors using these electrode barriers grown directly on $\mathrm{Si}$, show well saturated hysteresis loops with $P_{r}$ and $E_{c}$ of $16 \mu \mathrm{C} / \mathrm{cm}^{2}$ and $30-40 \mathrm{kV} / \mathrm{cm}$, respectively. The capacitors exhibit no significant fatigue loss $(<5 \%)$ up to $10^{11}$ cycles and have low leakage currents $\left(2 \times 10^{-8} \mathrm{~A} / \mathrm{cm}^{2}\right.$ at $\left.100 \mathrm{kV} / \mathrm{cm}\right)$. These electrode barriers can be used to directly integrate the thin film capacitors on the source/drain of the transistors of the memory cell structure for accomplishing large scale integration. (C) 1997 American Institute of Physics.

[S0003-6951(97)00724-4]

Dielectric and ferroelectric thin film capacitors have generated considerable interest due to their potential in applications involving dynamic random access memories (DRAMs) and nonvolatile random access memories (NvRAMs). ${ }^{1,2}$ A one transistor-one capacitor (1T-1C) memory cell structure has been proposed to accomplish very large scale integration of ferroelectric memory devices. ${ }^{3}$ This requires the bottom electrode of the capacitor to be in direct electrical contact with the source/drain of the transistor of the memory cell. A few structures investigated for this purpose as shown in Fig. 1(a) require the deposition of separate electrode and barrier layers. The electrode consists of two layers, metal (Pt,Ir,Ru) and conducting oxide (LSCO, YBCO, $\mathrm{RuO}_{2}, \mathrm{IrO}_{2}$ ) to improve the degradation properties of $\mathrm{PbZr}_{0.53} \mathrm{Ti}_{0.47} \mathrm{O}_{3}$ (PZT) ferroelectric capacitors. ${ }^{4-6}$ The diffusion barrier can include up to three different layers [TiN/ $\left.(\mathrm{Ti}, \mathrm{Ta}) /\left(\mathrm{TiSi}_{2}, \mathrm{TaSi}_{2}\right)\right]$ due to constraints of diffusion, oxidation resistance as well as adhesion. ${ }^{7}$ These structures are complicated, require the deposition of four/five different layers and also suffer from problems of adhesion as well as oxidation of the TiN layer for processing temperatures greater than $500{ }^{\circ} \mathrm{C}$.

In this letter, we report a novel multilayer electrodebarrier structure which has good electrical conductivity, high temperature stability, acts as an excellent diffusion barrier up to high processing temperatures $\left(\sim 700{ }^{\circ} \mathrm{C}\right)$, provides excellent adhesion with the ferroelectric/substrate, significantly reduces the degradation problems of fatigue and leakage current associated with PZT thin film capacitors and has tremendous potential for integration in the high-density memory cell structure. Figure 1(b) shows the schematic of the multilayer electrode structure. The electrode structure consists of a bottom platinum-rhodium-oxide layer ( $\mathrm{Pt}-\mathrm{Rh}-$ $\mathrm{O}_{x}$ ) in contact with the substrate, an intermediate $\mathrm{Pt}-\mathrm{Rh}$ metal layer and a top $\mathrm{Pt}-\mathrm{Rh}-\mathrm{O}_{x}$ layer in contact with the ferroelectric layer. The three layers of the electrode barriers are deposited using an in situ sputtering process consisting of sputtering the bottom oxide layer in $\mathrm{Ar}+\mathrm{O}_{2}$ ambient, the metal layer in pure Ar atmosphere and finally the top oxide layer in the $\mathrm{Ar}+\mathrm{O}_{2}$ ambient. Specifically, the electrode deposition conditions were as follows: The electrodes were deposited in a rf sputter system (Cooke Vacuum Products) using a Pt-10\% Rh alloy target (2 in. diam/0.125 in. thick). The electrodes were deposited at a substrate temperature of $450{ }^{\circ} \mathrm{C}$ and at $\mathrm{rf}$ power of $50 \mathrm{~W}$. The gas pressure used was $5 \mathrm{mT}$ Torr for pure $\mathrm{Ar}$ and $7 \mathrm{mT}$ for $\mathrm{Ar}+\mathrm{O}_{2}$. The $\mathrm{Ar} / \mathrm{O}_{2}$ ratio was kept constant at 20:4 sccm. The deposition times were 3 ,

(a)

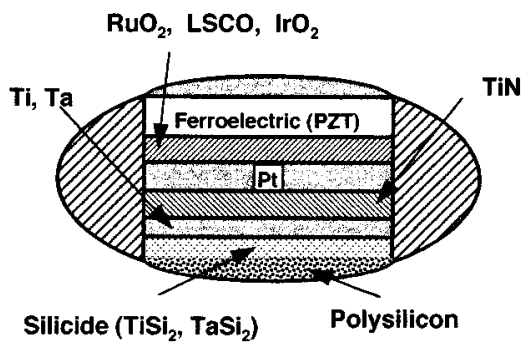

(b)

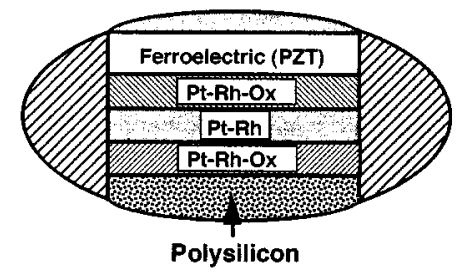

FIG. 1. Schematic of the magnified view of the capacitor on the source/ drain of the transistor in the 1T-1C structure for (a) structure using separate electrode and barrier layers and (b) proposed novel electrode-barrier structure. 
17, and $6 \mathrm{~min}$ for the top, intermediate, and bottom layers, respectively. The electrodes were deposited directly on single crystal $n^{+} \mathrm{Si}(100)$ and $n^{+}$ polycrystalline(poly)silicon $/ \mathrm{SiO}_{2} / \mathrm{Si}$ substrates. The substrates were cleaned and degreased and the surface H-passivated by using a HF acid treatment. The substrates were then immediately transferred to the sputter chamber to minimize any native oxide formation. Following the bottom electrode deposition, MOD derived PZT film of the composition $\mathrm{PbZr}_{0.53} \mathrm{Ti}_{0.47} \mathrm{O}_{3}$ was deposited from a metallorganic precursor, preparation details of which are described elsewhere. ${ }^{8}$ The thickness of the PZT film was determined by spectroscopic ellipsometry to be approximately $3000^{\circ} \mathrm{A}$. The films were then annealed at $650{ }^{\circ} \mathrm{C}$ for $30 \mathrm{~min}$ in a quartz tube furnace under flowing oxygen to accomplish crystallization of the perovskite phase in the PZT film. Next, the top electrodes were deposited through a shadow mask by sputtering, having identical structure and deposition conditions as the bottom electrodes and the specimens were then annealed at $600{ }^{\circ} \mathrm{C}$ for $30 \mathrm{~min}$. The top electrode area was approximately $3.0 \sim 10^{-4} \mathrm{~cm}^{2}$.

The composition and thickness of the electrode films was determined using the Rutherford backscattering spectroscopy (RBS) technique. The phase formation and orientation in the PZT film was studied using $\mathrm{x}$-ray diffraction (XRD). The morphology of the films was examined using atomic force microscopy (AFM). The ferroelectric properties (hysteresis and fatigue) of the capacitor structures were determined by using the RT66A ferroelectric tester from Radiant Technologies (Albuquerque, NM). The dc leakage current of these capacitors was determined using the Kiethley 617 programmable electrometer.

Results of the RBS studies on the as-deposited electrode films confirmed the oxide layer formation at the surface (top) and the electrode/substrate interface (bottom) due to reactive sputtering. The RBS simulation results indicate that there are three distinct layers in the deposited films, as expected. The bottom layer adjacent to the substrate is an oxide layer having the atomic composition Pt:Rh:O=66:14:20, the intermediate layer is a metallic layer of composition $\mathrm{Pt}: \mathrm{Rh}=87: 13$ and the top oxide layer having the composition Pt:Rh:O $=50: 20: 30$. The thickness of these layers corresponding to the deposition times of 3,17 , and 6 min was determined to be 15,50 , and $30 \mathrm{~nm}$, respectively. Based on the compositional results we cannot conclude conclusively whether the film is a complete mixed oxide film or a mixture of metallic and oxide components. The resistivity of the multilayer electrode-barrier films measured using the four-point probe was determined to be in the range of $18-24 \mu \Omega \mathrm{cm}$, indicating that the multilayer electrodes had comparable resistivities to the metallic films.

Figure 2 shows the RBS spectra of the multilayer electrode film as well as Pt film on $n^{+} \mathrm{Si}$ substrate after annealing at $700{ }^{\circ} \mathrm{C}$ for $60 \mathrm{~min}$ in flowing $\mathrm{O}_{2}$. The results clearly demonstrate that there is no significant interdiffusion between the $\mathrm{Pt}-\mathrm{Rh}$ and $\mathrm{Si}$ as compared to the $\mathrm{Pt} / \mathrm{Si}$ case (both the Pt and Si edges have shifted considerably). This indicates that the $\mathrm{Pt}-\mathrm{Rh}-\mathrm{O}_{x}$ layer acts as a very good diffusion/ reaction barrier up to processing temperatures of $700{ }^{\circ} \mathrm{C}$. The XRD data for the multilayer electrode films deposited on $\mathrm{Si}$

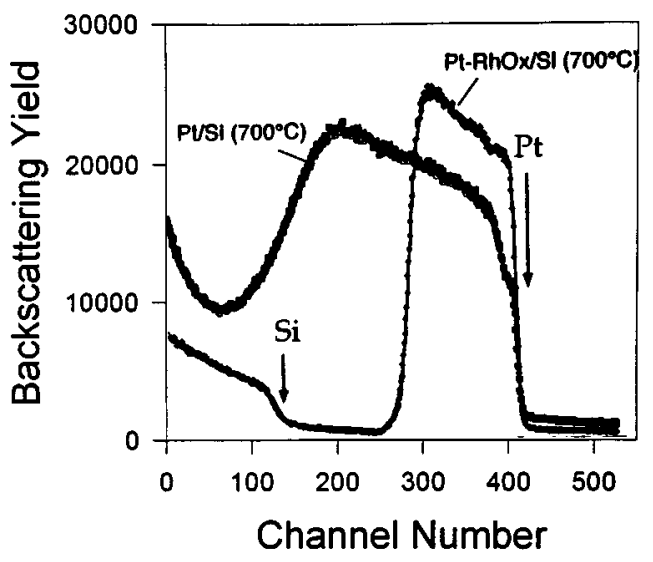

FIG. 2. RBS spectra of the multilayer electrode-barrier film and Pt film on $n^{+} \mathrm{Si}(100)$ after annealing at $700{ }^{\circ} \mathrm{C}$ for $60 \mathrm{~min}$ in $\mathrm{O}_{2}$.

substrate did not show any new peaks as compared to $\mathrm{Pt}$ corresponding to $\mathrm{Pt} / \mathrm{Rh}$ silicides after annealing at $650{ }^{\circ} \mathrm{C}$ demonstrating the barrier effect of the $\mathrm{Pt}-\mathrm{Rh}-\mathrm{O}_{x}$ layer. Morphological examination of the electrodes using the AFM showed that the electrodes have a uniform and a very fine grained structure with an average grain size of approximately $400^{\circ} \mathrm{A}$. In addition, no hillock formation was observed for these electrodes after annealing at $650{ }^{\circ} \mathrm{C}$ and the average surface roughness $R_{a}$ determined from the AFM data was only $0.68 \mathrm{~nm}$. Figure 3 shows the XRD pattern for the PZT film deposited on the bottom electrode/Si (100) structure and annealed at $650{ }^{\circ} \mathrm{C}$ for $30 \mathrm{~min}$ in $\mathrm{O}_{2}$ atmosphere. As observed from the XRD pattern, it appears that the films have predominantly crystallized in the ferroelectric perovskite phase. The films do not appear to have any preferred orientation. The PZT films have an average grain size of approximately $800^{\circ} \mathrm{A}$ as observed from the AFM micrographs. An important point to note here is the extreme smoothness of the PZT films which have an average roughness $R_{a}$ value of only $1.31 \mathrm{~nm}$ due to the smooth and fine grained textured of the underlying electrodes $\left(R_{a}=0.62 \mathrm{~nm}\right)$, as compared to films deposited on Pt electrodes due to the hillock formation problem of the underlying Pt electrodes. ${ }^{9}$ Therefore the multilayer electrodes have a significant advantage when used for thinner films of PZT as compared to the Pt electrodes.

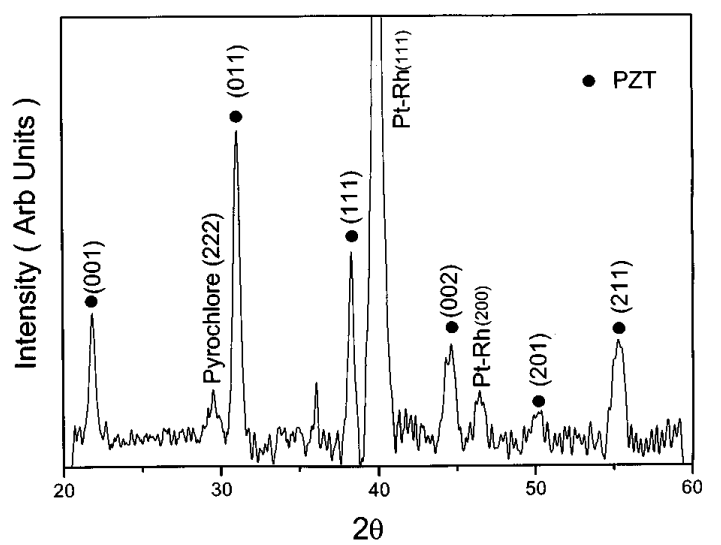

FIG. 3. XRD pattern of the PZT film deposited on the electrode-barrier $/ n^{+}$ $\mathrm{Si}$ (100) structure and annealed at $650{ }^{\circ} \mathrm{C}$ for $30 \mathrm{~min}$ in $\mathrm{O}_{2}$. 
(a)

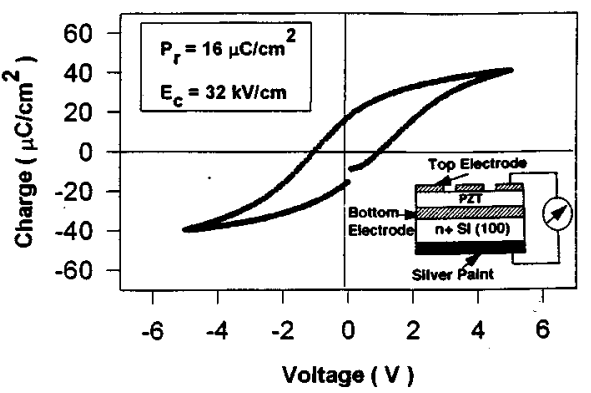

(b)

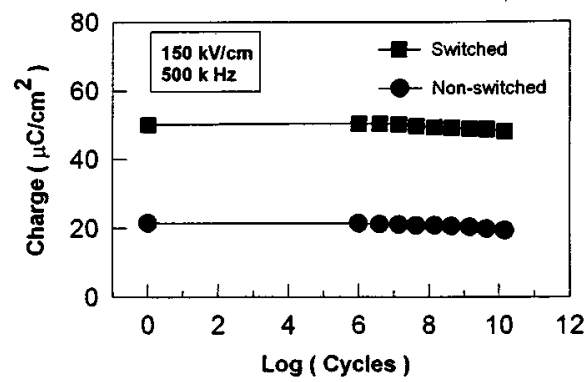

FIG. 4. Hysteresis curve (a) and fatigue behavior (b) of test capacitors with PZT on electrode-barrier structures deposited directly on $n^{+} \mathrm{Si}$ (100).

Figures 4(a) and 4(b) show the typical hysteresis curve and the fatigue behavior of the top electrode $\left(\mathrm{Pt}-\mathrm{Rh}-\mathrm{O}_{x} / \mathrm{Pt}-\mathrm{Rh} / \mathrm{Pt}-\mathrm{Rh}-\mathrm{O}_{x}\right) / \mathrm{PZT} /$ bottom electrode $\left(\mathrm{Pt}-\mathrm{Rh}-\mathrm{O}_{x} / \mathrm{Pt}-\mathrm{Rh} / \mathrm{Pt}-\mathrm{Rh}-\mathrm{O}_{x}\right)$ test structures deposited directly on $n^{+} \mathrm{Si}(100)$ substrate annealed at $650{ }^{\circ} \mathrm{C}$ for $30 \mathrm{~min}$ in $\mathrm{O}_{2}$. The electrical measurements were made through the $n^{+} \mathrm{Si}(100)$ layer between the top electrodes and the conducting silver paint applied at the bottom of the substrate as depicted in the test structure shown in the inset of Fig. 4(a). The hysteresis loop for these test structures is well saturated and shows the remnant polarization $P_{r}$ value of around 16 $\mu \mathrm{C} / \mathrm{cm}^{2}$. The coercive field $E_{c}$ is also low and falls in the range of $30-40 \mathrm{kV} / \mathrm{cm}$. The $P_{r}$ and $E_{c}$ values for the capacitors deposited on $n^{+}$poly $\mathrm{Si} / \mathrm{SiO}_{2} / \mathrm{Si}$ and $\mathrm{SiO}_{2} / \mathrm{Si}$ structures fall within the same range. The $P_{r}$ values for PZT films deposited on the multilayer electrodes are lower than the films deposited on Pt electrodes possibly due to the smaller grain size of PZT. Fatigue tests were performed using an externally generated square wave with an amplitude of \pm 5 $\mathrm{V}$ and a frequency of $500 \mathrm{KHz}$. In Fig. 4(b), the switched as well as unswitched charge is plotted as a function of log cycles applied to the capacitors. Results of the fatigue testing show that there is no significant fatigue (polarization loss $<5 \%$ ) up to $10^{11}$ cycles. Figure 5 shows the dependence of the dc leakage current on applied voltage and polarity [top electrode $(+)$ or bottom electrode $(+)$ ] for the test structures on $n^{+} \mathrm{Si}(100)$ substrate. The leakage current increases very slightly up to applied field of $100 \mathrm{kV} / \mathrm{cm}$ which is followed by a linear increase up to applied fields of $500 \mathrm{kV} / \mathrm{cm}(\log$ $J \mathrm{v} / \mathrm{s} E^{0.5}$ dependence). This behavior is indicative of either a Poole-Frankel or Schottky Barrier controlled mechanism. However, different values of the leakage current with respect to a polarity change during measurement implies that the Schottky barrier is the dominant leakage current mechanism. The leakage current at applied field of $100 \mathrm{kV} / \mathrm{cm}(3 \mathrm{~V})$ has

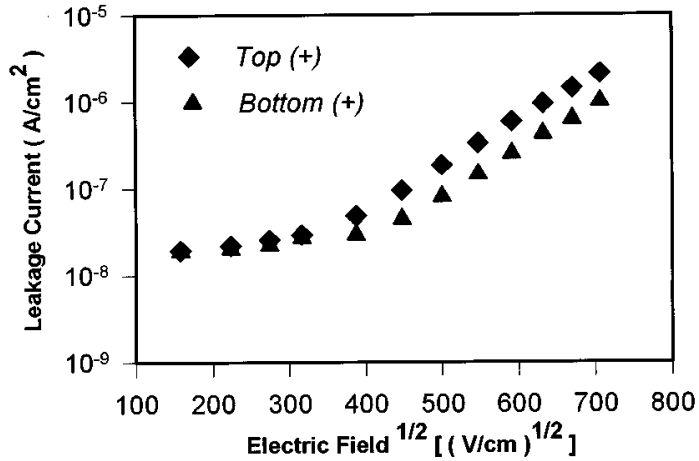

FIG. 5. Dependence of dc leakage current on root applied electric field $E^{0.5}$ and polarity for the test capacitors on electrode-barrier structures deposited directly on $n^{+} \mathrm{Si}(100)$.

a low value of $2 \times 10^{-8} \mathrm{~A} / \mathrm{cm}^{2}$ and is comparable to PZT on Pt electrodes.

In conclusion, we have successfully fabricated ferroelectric (PZT) test capacitor structures directly on $\mathrm{Si}\left[n^{+} \mathrm{Si}\right.$ (100) and $n^{+}$poly Si] using $\mathrm{Pt}-\mathrm{Rh}-\mathrm{O}_{x} / \mathrm{Pt}-\mathrm{Rh} / \mathrm{Pt}-\mathrm{Rh}-\mathrm{O}_{x}$ multilayer electrode barriers with excellent ferroelectric and fatigue characteristics. The test capacitors show well saturated hysteresis loops with $P_{r}$ and $E_{c}$ of $16 \mu \mathrm{C} / \mathrm{cm}^{2}$ and $30-40 \mathrm{kV} / \mathrm{cm}$, respectively. The capacitors exhibit no significant fatigue loss up to $10^{11}$ cycles and have low leakage currents $\left(2 \times 10^{-8}\right.$ at $\left.100 \mathrm{kV} / \mathrm{cm}\right)$. The multilayer electrode structure acts as an excellent barrier between the ferroelectric film and the Si substrate up to high processing temperatures of $700{ }^{\circ} \mathrm{C}$ and also significantly improves the degradation properties of these capacitors. The barrier properties of this multilayer electrode structure should make it possible to integrate ferroelectric [PZT, $\mathrm{SrBi}_{2} \mathrm{Ta}_{2} \mathrm{O}_{9}$ (SBT), etc.] or high dielectric constant paraelectric $\left[\mathrm{Ba}_{1-x} \mathrm{Sr}_{x} \mathrm{TiO}_{3}\right.$ (BST), etc.] capacitors in the large scale integrated memory (NvRAM and DRAM) cell structures.

The authors would like to thank Sharp Corporation, Japan, CERAM-VA and CIT-VA for funding this research.

${ }^{1}$ J. F. Scott and C. A. Araujo, Science 246, 1400 (1989).

${ }^{2}$ D. P. Vijay, S. B. Desu, M. Nagata, X. Zhang, and T. C. Chen, Mater. Res. Soc. Symp. Proc. 361, 3 (1994).

${ }^{3}$ S. Yokoyama, Y. Ito, K. Ishihara, K. Hamada, S. Ohnishi, J. Kudo, and K. Sakiyama, Jpn. J. Appl. Phys. 34, 767 (1995).

${ }^{4}$ R. Ramesh, W. K. Chan, B. Wilkens, H. Gilchrist, T. Sands, J. M. Tarascon, V. G. Keramdas, D. K. Fork, J. Lee, and A. Safari, Appl. Phys. Lett. 61, 1537 (1992).

${ }^{5}$ I. Chang, J. K. Lee, W. I. Lee, C. W. Chung, and S. B. Desu, Mater. Res. Soc. Symp. Proc. 361, 249 (1994).

${ }^{6}$ T. Nakamura, Y. Nakao, A. Kamisawa, and H. Takasu, Jpn. J. Appl. Phys. 33, 5207 (1994).

${ }^{7}$ K. Shoji, M. Moniwa, H. Yamashita, T. Kisu, T. Kaga, K. Toril, T. Kumihashi, T. Morimoto, H. Kawakami, Y. Gotoh, T. Itoga, T. Tanaka, N. Yokoyama, T. Kure, M. Ohkura, Y. Fujisaki, K. Sakata, and K. Kimura, VLSI Tech. Symposium Digest of Technical Papers, 28 (1996).

${ }^{8}$ G. Yi and M. Sayer, Ceram. Bull. 70, 1173 (1991).

${ }^{9}$ J. O. Olowolfe, R. E. Jones, Jr., A. C. Campbell, R. I. Hegde, C. J. Mogab, and R. B. Gregory, J. Appl. Phys. 73, 1764 (1993). 